\title{
English Toy Spaniel
}

National Cancer Institute

\section{Source}

National Cancer Institute. English Toy Spaniel. NCI Thesaurus. Code C53950.

The Eng lish Toy Spaniel is a small, square spaniel with a deep, pug nose. The long feathered ears are pendant and hang along its cheeks. The soft coat is well feathered and comes in four colors varieties: King Charles (black and tan), Ruby (solid red, sometimes with a few white hairs or small white patch on the chest), Blenheim (white with red markings, often with a red "thumb print" centered on the top of the head), and Prince Charles (tri-color: white with black and tan markings). Height: about 10 inches (25 cm.) Weight: 9-12 pounds (4.1-5.4 kg.) 